\title{
Long-term results of augmentation cystoplasty in spinal cord injury patients
}

\author{
EJ Chartier-Kastler*, ${ }^{*}$, P Mongiat-Artus ${ }^{1}$, MO Bitker ${ }^{1}$, MB Chancellor ${ }^{2}$, F Richard ${ }^{1}$ and P Denys ${ }^{3}$ \\ ${ }^{1}$ Department of Urology, Pitié-Salpétrière Hospital, University Pierre et Marie Curie (Paris VI) Paris, France; \\ ${ }^{2}$ Department of Urologic Surgery, Neuro-urology and Urinary Incontinence Programs, University of Pittsburgh \\ School of Medicine, Pittsburgh, PA, USA; ${ }^{3}$ Department of Neurological Rehabilitation, Raymond Poincaré Hospital, \\ University Paris-Ouest, Garches, France
}

\begin{abstract}
Study design: Prospective monocentric follow-up study.
Objectives: To assess long-term functional and urodynamic results of augmentation enterocystoplasty in spinal cord injury (SCI) patients with detrusor hyperreflexia and reflex incontinence who failed to respond to conservative treatment.

Settings: Department of Urology (Pitié-Salpétrière Hospital, Paris, France), Department of Neurological Rehabilitation (Raymond Poincaré Hospital, Garches, France), Assistance Publique - Hopitaux de Paris, University Paris VI and V, France.

Methods: Prospective study of 17 SCI patients (four above T6 level, nine between T6 and $\mathrm{T} 12$, and four below T12) with history of refractory urge incontinence to pharmacotherapy. Partial cystectomy (subtrigonal for 15) was performed with Hautmann enterocystoplasty (15) or detubularized clam cystoplasty (two).

Results: Mean follow-up was $6.3 \pm 3.8$ years (range $1.25-10.5$ years). Fifteen of 17 (88.5\%) patients were completely continent under self clean intermittent catheterization (CIC) (mean 4.6/day, range 4-7). The remaining two patients with pudendal nerve denervation had persistent stress urinary incontinence. No operative complications were noted. Long-term complications included recurrent pyelonephritis for one patient. Maximal cystometric capacity increased from $174.1 \pm 103.9$ to $508.1 \pm 215.8 \mathrm{ml}(P<0.05)$. Maximal end filling pressure decreased from $65.5 \pm 50.2$ to $18.3 \pm 7.9 \mathrm{~cm} \mathrm{H}_{2} \mathrm{O}(P<0.05)$.

Conclusion: Urodynamic evaluation and clinical assessment demonstrate long-term success of augmentation enterocystoplasty in an homogeneous population (SCI) without delayed complications in SCI patients.
\end{abstract}

Spinal Cord (2000) 38, 490-494

Keywords: neurogenic bladder; spinal cord injury; incontinence; enterocystoplasty; urodynamics

\section{Introduction}

Safe urologic management of SCI patients should encompass maintenance of normal renal function. Key goals of urological management include maintenance of a low pressure bladder, avoiding high residual urine volume, free of pyelonephritis, and achieving urination. ${ }^{1-3}$ Clean intermittent catheterization (CIC) and parasympatholytic drugs are our method of choice to reach these goals. ${ }^{4-7}$

CIC may not be as effective if the bladder is hyperreflexive with detrusor-sphincter dyssynergia., ${ }^{4,6}$ When CIC plus anticholinergic program failed to create an adequate bladder volume with lower pressure during storage, bladder augmentation is generally considered. $^{8}$ The purpose of this study is to assess

*Correspondence: E Chartier-Kastler, Service d'Urologie, G.H. PitiéSalpétrière, 83, Boulevard de l'Hôpital, 75013 Paris, France the possibility of augmentation cystoplasty to achieve safe long-term urologic management in SCI patients. Little is known about long-term results (over 5 years) in this specific population of patients. ${ }^{9}$ We prospectively evaluated $17 \mathrm{SCI}$ patients who underwent enterocystoplasty.

\section{Materials and methods}

From 1988 to 1998,17 spinal cord injury patients were prospectively evaluated after augmentation ileocystoplasty. There were 11 men and six women. The levels of injury were above T6 level in four patients, nine patients between T6 and T12, and four patients below T12. Spinal cord injuries were related to traffic crashes $(n=16)$ and self injury in one. The average duration of SCI was 7.5 years (range $2-16$ years). Complete spinal 
cord lesions (Frankel A) was reported in 14 of 17 patients. The average age was 36.5 years (39 years old for male and 33 years old for female patients). Relevant past medical history in the patient population included a sphincterotomy in two male patients and unilateral nephrectomy for chronic reflux and recurrent pyelonephritis in three patients (Table 1).

Among the 17 patients, 15 performed CIC (up to 10 times a day) but suffered refractory urge incontinence despite a maximum of two anticholinergic drugs pharmacotherapy. One other patient had incontinence despite indwelling urethral catheter because of failure of CIC plus anticholinergic drugs. The last one had a bilateral ureterostomy for a post-traumatic infected pelvic hematoma and prostato-rectal fistula. He asked for urinary reconstruction 12 months after trauma.

The upper urinary tract was pre-operatively dilated in eight patients. Renal failure occurred in two of them: one (male) with past chronic evolution (preoperative creatinine level $<200 \mu$ moles/l, creatinine clearance $45 \mathrm{ml} / \mathrm{min}$ ) because of vesicoureteral reflux, the second (female) was first referred to the department of urology for acute renal insufficiency. It resolved with bilateral ureteral catheters without any acquired functional damage, waiting for secondary enterocystoplasty with bilateral ureteral reimplantation.

\section{Pre-operative urodynamics evaluation}

All patients underwent careful preoperative urodynamics assessment using ICS recommendations. A room temperature fluid filling was used $(50 \mathrm{~mL} / \mathrm{min})$. Twelve patients had a small hyperreflective blader (maximal cystometric capacity below $250 \mathrm{ml}$, five with detrusor-sphincter dyssynergia). Five patients had a hyperreflective bladder with maximal cystometric capacity above $250 \mathrm{ml}$. All the patients had decreased bladder compliance ( $<$ to $10 \mathrm{ml} / \mathrm{cm} \mathrm{H}_{2} \mathrm{O}$ ) including patients with previous sphincterotomy. Maximal end filling pressure was $65.5 \pm 50.2 \mathrm{~cm} \mathrm{H}_{2} \mathrm{O}$. The average urethral closure pressures were $13.5 \mathrm{~cm} \mathrm{H}_{2} \mathrm{O}$ for female $(n=6)$ and $44 \mathrm{~cm} \mathrm{H}_{2} \mathrm{O}$ for male $(n=11)$ patients.

\section{Surgical technique}

All patients underwent a partial cystectomy, most of them subtrigonal $(n=15)$ : the bladder dome was sagitally opened and excised up to $2 \mathrm{~cm}$ from its base. A segment of reconfigured ileum was anastomosed to the remaining bladder base. Our first two patients were operated on with a clamshell-detubularized cystoplasty involving $20 \mathrm{~cm}$ of ileum. For the subsequent 15 patients, we used $60 \mathrm{~cm}$ ileum that is located $25-40 \mathrm{~cm}$ from the ileo-caecal valvule. The isolated ileal segment was detubularized into a ' $\mathrm{W}$ ' shape as described by the Hautmann ${ }^{10}$ procedure. Five patients with high-grade vesicoureteral reflux underwent reimplantation following the LeDuc-Camey procedure. ${ }^{11}$ An indwelling urethral catheter was used for 13 days.

One male patient had the additional implantation of a peri-prostatic cuff of artificial urinary sphincter because of severe sphincteric insufficiency, without implanting the remaining part of the device. One female patient had had a successful Burch colposuspension before surgery for mixed incontinence (Table $1)$.

\section{Follow-up}

Urologic follow-up included visits at 1, 3, 6, 12 months and then yearly. It consisted of history and physical examination, laboratory evaluation, and neo-bladder (stone screening) and renal ultrasound (upper urinary tract dilatation screening). Cystometries were planned to be performed each year during the first 5 years of follow-up, thereafter according to symptoms. Cystography was initially performed yearly when vesicoureteral reflux preexisted, and radionuclear renal scan was used for the patient with chronic renal failure. If normal it was replaced by a yearly renal ultrasound examination before and after CIC looking for upper urinary tract dilatation.

\section{Data analysis}

All values are presented as mean \pm SD. Statistical analysis was done using the Student's $t$-test. A probability level of less than 0.05 was considered significant.

\section{Results}

The mean follow up was $6.3 \pm 3.8$ years (range $1.25-$ 10.5 years). Fifteen of $17(88.2 \%)$ patients reported a

Table 1 Prior surgery related to the urinary tract

\begin{tabular}{lcl}
\hline $\begin{array}{l}\text { Previous surgery before } \\
\text { augmentation cystoplasty }\end{array}$ & $\begin{array}{c}\text { Number of } \\
\text { patients }\end{array}$ & Comments \\
\hline Nephrectomy & 3 & Loss of infected kidneys because of uretero-vesical reflux \\
Sub-ureteral injection $\left(\right.$ Teflon ${ }^{\circ}$ ) & 3 & All failures \\
Sphincterotomy (among $11 \mathrm{males}^{2}$ & 2 & $\begin{array}{l}\text { Patients became unhappy with condom catheters } \\
\text { Colpocystopexy (among six females) }\end{array}$ \\
$\begin{array}{lll}\text { Uretero-vesical reimplantation } & 1 & \text { Indication: mixed incontinence. Prolonged incontinence due to } \\
\text { neurogenic bladder }\end{array}$ \\
\hline
\end{tabular}


high continence rate and symptomatic improvement: 12 patients were completely dry, including the two patients who had prior sphincterotomies. Three patients (two males and one female) occasionally (one time a half-month) experienced stress incontinence and/ or nighttime leakage that did not hamper their social activity when bladder filling was more than $500 \mathrm{ml}$. Five patients still needed an anticholinergic drug to increase functional bladder capacity and to decrease frequency of catheterization.

These 15 dry patients performed CIC a mean of 4.5 times per day (range 4-7). No patient reported postop urge incontinence. There was one case of traumatic catheterization in male with a prostatic urethra false passage 6 years post augmentation. It was successfully treated with a simple endoscopic prostatic incision.

The remaining two male patients had persistent severe stress urinary incontinence despite bladder augmentation. However, both of them had had damage and denervation of the external sphincter due to multiple pelvic fracture at the time of SCI. More surprising, the main feature that distinguished these two patients was the failure in performing CIC (lack of motivation) leading to no reoperation for a better continence.

Post-operative urodynamic results $(n=17)$ are listed on Table 2 and compared to preoperative data. Maximal cystometric capacity increased by a mean of $191 \%$ while the maximal end filling pressure decreased by $72 \%$ (all differences are statistically significant, $P<0.05$ ). Six patients had uninhibited contractions during filling phase, always below $40 \mathrm{~cm} \mathrm{H}_{2} \mathrm{O}$ that were not correlated to any leakage during urodynamics study.

Serum creatinine remained unchanged, even for the patient bearing chronic renal failure. Neither anemia nor electrolyte abnormality was diagnosed. No kidney unit has been lost. Bacteriuria occurred in five patients.

No other peri-operative and short-term complications related to surgery have been encountered. There was no death. No bowel obstruction appeared, two patients suffered prolonged ( $>7$ days) ileus and hindgut inertia that spontaneously resolved. One acute pyelonephritis had to be treated at day 4 without any consequence (ureteral catheters were present). Mean hospital stay was 21 days, seven

Table 2 Urodynamics data of patients at baseline and after augmentation enterocystoplasty. Post-op data were collected at the last urodynamics study performed (mean 5.4 years)

\begin{tabular}{lcc}
\hline & $\begin{array}{c}\text { Pre-op } \\
(n=17)\end{array}$ & $\begin{array}{c}\text { Post-op } \\
(n=17)\end{array}$ \\
\hline $\begin{array}{l}\text { Maximal cystometric capacity } \\
(\mathrm{ml})\end{array}$ & $174.1 \pm 103.9$ & $508.1 \pm 215.8^{*}$ \\
End filling pressure $\left(\mathrm{cm} \mathrm{H}_{2} \mathrm{O}\right)$ & $65.5 \pm 50.2$ & $18.3 \pm 7.9^{*}$ \\
\hline
\end{tabular}

*Statistically significant difference, Student's $t$-test, $P<0.05$ hospitalizations were longer than 30 days because of waiting for rehabilitation center placement.

Long-term complications included recurrent acute pyelonephritis for one female patient (at least one per year). These severe kidney infections led to recurrent hospitalizations and were related to a right neobladder to kidney reflux. She was non compliant with scheduled CIC and was doing the Crede maneuver most of the time. This patient was continent with a bladder capacity up to $1200 \mathrm{ml}$. She was planned to a future cutaneous diversion to prevent these episodes. Her creatinine level stayed stable and normal $(95 \mathrm{mmol} / \mathrm{l})$. The patient with artificial urinary sphincter (AUS) implanted (cuff only) developed prosthesis infection and the AUS was explanted after 6 months. He remained continent despite pre-op urethral closure pressure $25 \mathrm{~cm} \mathrm{H}_{2} \mathrm{O}$ and an open bladder neck on cystography.

No spontaneous rupture of bladder appeared during follow-up, nor lithiasis. No bowel dysfunction appeared after surgery and no patient complained diarrhea.

\section{Discussion}

Augmentation enterocystoplasty was successful for more than 6 years in $88 \%$ of our SCI population. Augmentation cystoplasty, when it was first introduced, was thought to be unsafe for SCI patients. ${ }^{12,13}$ More recent data has established augmentation cystoplasty as a safe and effective procedure that can help $80 \%$ to $95 \%$ of patients achieving dryness and perineal protection and also protects the upper urinary tract. ${ }^{14}$ Although augmentation is an effective surgery. To our knowledge, this efficacy has not yet been so well described with long-term results ( $>5$ years) in this very specific SCI population.

Worsening of bowel dysfunction may be a major complication of bladder reconstruction. ${ }^{15,16} \mathrm{Up}$ to $29 \%$ of the patients who underwent bladder augmentation regretted having the procedure due to subsequent bowel symptoms: increased bowel frequency, looser consistency, needed more help for evacuation and increased incontinence episodes. ${ }^{16,17}$ Wood $^{18}$ reported recently a $16 \%$ rate of his population with distressing chronic diarrhea after enterocystoplasty. This dysfunction can be related to coecum use (reducing long-term absorptive function) and ileocecal valve resection, which can compromise gastrointestinal transit sites. None of our patients had bowel dysfunction after the first post-operative month. As no modification was made in the post-operative and intensive care unit management of patients, it appears to be probably related to the surgical technique (no use of right colon).

We believe subtrigonal cystectomy at the time of bladder augmentation in SCI patients has to remove as much as possible pathologic bladder tissue. The goal of surgery is to obtain bladder enlargement for a low pressure and high capacity reservoir. Native tissue 
is unable to achieve this goal at time of surgery and a better result can be obtained with new and compliant tissue (bowel). Given this fact, quality of bladder tissue has to be assessed during surgery and can be preserved if thin and without any hypertrophy leading to a reduced length of bowel use. We succeeded in two patients with good functional results. The remaining part of the bladder could be a reason for anticholinergic drugs use in five patients. This did not appear to be correlated to any urodynamic data regarding neo-bladder contractions and these drugs have been prescribed to achieve a better bladder capacity during catheterization.

It has been shown that combined simultaneous bladder outlet procedure and augmentation cystoplasty satisfactorily achieve continence without additional complication, even if artificial urinary sphincter is implanted. ${ }^{8,19-22} \mathrm{We}$ had two male patients who previously had a sphincterotomy and became continent up to 2 years after bladder augmentation without any other surgery for augmentation of outlet resistance. For the two patients who demonstrated obvious stress incontinence leakage, one underwent an undiversion, which is known to be associated with a higher complication rate, ${ }^{23}$ and the other presented with complex pelvic trauma (bone fractures and bladder injury) in addition to the spinal cord trauma.

In SCI, we believe the augmentation cystoplasty is able to treat refractory urge incontinence related to bladder hyperreflexia with concomitant upper urinary tract preservation. However this procedure is irreversible as are other surgical procedures, e.g. autoaugmentation $^{24,25}$ and Brindley procedure. ${ }^{26,27}$ The sacral deafferentation and combined implantation of an anterior sacral root stimulator that he described is a validated alternative which can be considered for complete spinal cord injury patients only, specially if patients ask for suppression of SCIC which is achieved for more than $85 \%$ of implanted patients. Moreover sacral deafferentation strongly impaired sexual function. Functional results of auto-augmentation remains a controversial issue. ${ }^{25}$ The more recent publication of Stöhrer et $a l^{28}$ seems to be more optimistic regarding bladder capacity and the low morbidity. Nevertheless, as in augmentation ileo-cystoplasty, the use of this technique needs patients' cooperation for SCIC and indication for a bladder surgery still remains related to failure of conservative medical treatment (anticholinergic drugs).

There is a need for reversible and conservative alternative therapies. Some are under development and investigation such as intravesical vanilloid agents, ${ }^{29}$ intrathecal clonidine ${ }^{30,31}$ or botulinum A-Toxin detrusor injections. ${ }^{32,33}$ These could be specific alternatives to all surgical techniques for the future.

\section{Conclusion}

In a specific population of SCI, augmentation enterocystoplasty demonstrates long-term (over 5 years) clinical and urodynamics results and efficacy. Associated medical treatments and surgical procedure were discussed. Results of future new and minimal invasive therapies will have to take these into account for comparison in terms of upper urinary tract protection and continence with CIC.

\section{References}

1 Donnelly J, Hackler R, Bunts R. Present urological status of the World War II paraplegic: 25 year follow-up. Comparison with status of the 20-year Korean War paraplegic and 5-year Vietnam War paraplegic. J Urol 1972; 108: 558 - 562.

2 Fam B, et al. Experience in the urologic management of 120 early spinal cord injury patients. J Urol 1978; 119: 485-487.

3 Graham S. Present urological treatment of spinal cord injury patients. J Urol 1981; 126: $1-4$.

4 Wyndaele J, De Sy W, Claessens H. Evaluation of different methods of bladder drainage used in the early care of the spinal cord injury patient. Paraplegia $1985 ; 23$ : $18-26$.

5 Wyndaele J. Urology in the spinal cord injured patients. Paraplegia 1987; 25: 26-29.

6 Wyndaele J, Maes D. Clean intermittent self catheterization: a 12 years follow-up. J Urol 1990; 145: $906-910$

7 Nanninga J, Wu Y, Hamilton B. Long term intermittent catheterization in the spinal cord injury patient. J Urol 1982; 128: $760-763$

8 Sidi A, et al. Augmentation enterocystoplasty for the management of voiding dysfunction in spinal cord injured patients. $J$ Urol 1990; 143: $83-85$.

9 Kuo H. Clinical outcome and quality of life after enterocystoplasty for contracted bladders. Urol Int 1997; 58: 160-165.

10 Hautmann R, et al. The ileal neobladder. J Urol 1988; 139: 39 42.

11 Le Duc A, Camey M, Teillac P. An original antireflux ureteroileal implantation technique: Long term follow-up. $J$ Urol 1987; 137: 1156-1158.

12 Winter C, Goodwin W. Results of sigmoidocystoplasty. J. Urol 1958; 137: $467-469$

13 Smith R, et al. Augmentation cystoplasty: a critical review. $J$ Urol 1981; 126: $741-745$.

14 Barrett D, et al. Surgery for the neuropathic patient (Committee 20). In: Abrams P, Khoury S, Wein A (eds). Incontinence. London: Health Publication Limited; 1999, pp 813-816.

15 Barrington $\mathrm{J}$, et al. Bile acid dysfunction after clam enterocystoplasty. Brit J Urol 1995; 76: 169-171.

16 Singh G, Thomas D. Bowel problems after enterocystoplasty. $\mathrm{Br}$ J Urol 1997; 79: $328-332$.

17 N'Dow J, et al. Bowel dysfunction after bladder reconstruction. $J$ Urol 1998; 159: 1470-1474.

18 Wood G, Heathcote P, Nicol D. Bowel mobility after enterocystoplasty. Br J Urol 1998; 81: $565-568$.

19 Singh G, Thomas D. Enterocystoplasty in the neuropathic bladder. Neurourol Urodyn 1995; 14: 5-10.

20 Mast $\mathrm{P}$, et al. Experience with augmentation cystoplasty. Paraplegia 1995; 33: 560-564.

21 Theodorou $\mathrm{C}$, et al. Combined reconstructive and prosthetic surgery in complicated ower urinary tract dysfunction. J Urol 1997; 157: 472 - 474

22 Fontaine $\mathrm{E}$, et al. Combined modified rectus fascial sling and augmentation ileocystoplasty for neurogenic incontinence in women. J Urol 1997; 157: 109-112.

23 Gonzalez R, Sidi A, Zhang G. Urinary diversion: indications, techniques and results in 50 cases. J Urol 1986; 136: 13-16.

24 Leng W, et al. Enterocystoplasty or detrusor myectomy? Comparison of indications and outcomes for bladder augmentation. J Urol 1999; 161: 758-763.

25 Hohenfellner M, et al. Orthotopic bladder augmentation and substitution. Curr Opin Urol 1999; 9: 309-314. 
26 Brindley G. The first 500 sacral anterior root stimulator implants: general description. Paraplegia 1994; 32: 795-805.

27 Brindley G. The first 500 sacral anterior root stimulators: implant failure and their repair. Paraplegia 1995; 33: 5-9.

28 Stöhrer $\mathrm{M}$, et al. Bladder autoaugmentation in adult patients with neurogenic voiding dysfunction. Spinal Cord 1997; 35: 456462.

29 Chancellor M, De Groat W. Intravesical capsaicin and resiniferatoxin therapy: spicing-up the ways to treat the overactive bladder. J Urol 1999; 163: 3-11.

30 Denys $\mathrm{P}$, et al. Intrathecal clonidine for refractory detrusor hyperreflexia in spinal cord injured patients: a preliminary report. J Urol 1998; 160: 2137-2138.
31 Chartier-Kastler E, et al. Intrathecal catheter with subcutaneous port for clonidine test bolus injection: a new route and type for detrusor hyperreflexia in spinal cord injury. Eur Urol 2000; 37: $14-17$.

32 Schurch B, Schmid D, Stöhrer M. Treatment of neurogenic incontinence with botulinum toxin A. NEJM 2000; 342: 665.

33 Stöhrer M, et al. Botulinum-A toxin detrusor injections in the treatment of detrusor hyperreflexia. J Urol 2000; 163(4 Suppl): abstract 1084 p 244 